\title{
Evaluation of anti-ulcer activity of the leaf extract of Osyris quadripartita Decne. (Santalaceae) in rats
}

\author{
This article was published in the following Dove Press journal: \\ Journal of Experimental Pharmacology \\ 16 January 2017 \\ Number of times this article has been viewed
}

\section{Mastewal Abebaw \\ Bharat Mishra \\ Dessalegn Asmelashe Gelayee}

Department of Pharmacology, College of Medicine and Health Sciences, University of Gondar, Gondar, Ethiopia
Correspondence: Dessalegn Asmelashe Gelayee

Department of Pharmacology, College of Medicine and Health Sciences, University of Gondar, PO Box 196, Gondar, Ethiopia

Email desefikir@gmail.com
Abstract: Osyris quadripartita (OQ) Salzm. ex Decne. has been used to treat peptic ulcer disease in Ethiopian folk medicine, but its efficacy has not been validated. The present study was therefore carried out to evaluate the anti-ulcer activity of $80 \%$ methanol leaf extract of OQ in rats. The effect of OQ extract on gastric ulcer in rats in pylorus ligation-induced and ethanol-induced models was studied using single dosing $(100,200,400 \mathrm{mg} / \mathrm{kg})$ and repeated dosing (200 mg/kg for 10 and 20 days) approaches. Ranitidine $(50 \mathrm{mg} / \mathrm{kg})$ and sucralfate (100 $\mathrm{mg} / \mathrm{kg}$ ) were used as the standard drugs. Depending on the model, outcome measures were volume and $\mathrm{pH}$ of gastric fluid, total acidity, ulcer score, percent inhibition of ulcer score, ulcer index as well as percent inhibition of ulcer index. Data were analyzed using one-way analysis of variance followed by Tukey's post hoc test, and $P<0.05$ was considered as statistically significant. OQ significantly $(P<0.001)$ reduced gastric ulcer index by $55.82 \%$ and $62.11 \%$, respectively, in pylorus ligation-induced and ethanol-induced ulcer models at the $400 \mathrm{mg} / \mathrm{kg}$ dose, which is comparable to the standard drugs. Ten and 20 days pre-treatment with OQ200 exhibited significant $(P<0.001)$ ulcer inhibition by $66.48 \%$ and $68.36 \%$ (pylorus ligation-induced model) as well as $71.48 \%$ and $85.35 \%$ (ethanol-induced model), respectively. OQ possesses both dose-dependent and time-dependent anti-ulcer effect in the two models. The oral median lethal dose $\left(\mathrm{LD}_{50}\right)$ is estimated to be higher than $2000 \mathrm{mg} / \mathrm{kg}$ for the crude hydroalcoholic extract, and secondary metabolites such as flavonoids, tannins, and saponins were present. The findings of this study confirmed that OQ has anti-ulcer pharmacologic activity due to one or more of the secondary metabolites present in it. Therefore, this study validates its anti-ulcer use in Ethiopian folk medicine. Further investigations on isolation of specific phytochemicals and elucidating mechanisms of action are needed.

Keywords: anti-ulcer activity, in vivo, Osyris quadripartita, rat

\section{Introduction}

Peptic ulcer disease and its complications remain the cause of significant morbidity worldwide, representing a major burden for health care resources. ${ }^{1}$ Although potent antiulcer drugs are available, most of them produce several toxicities, thus emphasizing the need to search for new alternatives. ${ }^{2}$ As high as $80 \%$ of the world population depends on plant-derived medicines for the first line of primary health care, ${ }^{3}$ reinforcing the theory that plant extracts can be good sources of new drugs. Ethiopia is a country characterized by a wide range of climatic and ecological conditions possessing enormous diversity of flora and fauna, including a wide range of potentially useful medicinal plants. The genus Osyris includes more than 34 species and belongs to the family Santalaceae. Osyris quadripartita (OQ) Salzm. ex Decne. (locally called qeret in Amharic and 
wato in Afaan Oromoo) is an evergreen, dioecious tree or shrub reaching a height of 1-7 $\mathrm{m}$ with many branches and the branches sometimes pendant. ${ }^{4}$ It is hemiparasitic and may opportunistically tap into the root systems of nearby plants and parasitize them, although it can freely grow and survive. ${ }^{5}$ It grows on rocky slopes and degraded woodland and scrub with an altitude of $1600-2900 \mathrm{~m}$. $^{6}$ The plant, which is native to Africa, Southwestern Europe, and Asia, is commonly known as wild tea plant. It is widely distributed in Ethiopia ${ }^{4}$ and used traditionally to treat peptic ulcer disease, cancer, toothache, malaria, skin lesion, abdominal pain, and urine problems among others. ${ }^{7-12}$ Several studies have been carried out to evaluate pharmacologic effects of OQ. It reduces capillary permeability associated with inflammation ${ }^{13}$ and has antioxidant, ${ }^{14}$ antibacterial, and antifungal ${ }^{6}$ as well as antimalarial ${ }^{10}$ activities. Phytochemicals such as polyphenols (flavonoids, lignans, coumarins), anthracene derivatives, and sesquiterpene lactones ${ }^{14}$ are present. OQ not only has several pharmacologic effects, but also it lacks acute toxic effect. ${ }^{10}$

\section{Methods and materials} Chemicals and drugs

Glacial acetic acid (Sigma -Aldrich Chemie, Steinheim, Germany), benzene (Nice Laboratory Reagent, Kerala, India), chloroform (Super TeK chemicals, Uttar Pradesh, India), ethanol (Indenta Chemicals, Mumbai, India), ferric chloride (Super Tek Chemicals), lead acetate trihydrate (Guangdong Chemical Reagent Engineering, Guangdong, People's Republic of China), mercuric chloride (Super Tek Chemicals), methanol (Nice Chemicals, Kochi, India), potassium iodide (Super Tek Chemicals), ranitidine (Cadila Pharmaceuticals, Bengaluru, India), sucralfate (Moraceae Pharmaceuticals Pvt. Ltd, Lucknow, India), sulfuric acid (Hi Media Laboratories Pvt. Ltd, Mumbai, India), hydrochloric acid (Nice Laboratory Reagent), sodium hydroxide (Rankem, Mumbai, India), and phenolphthalein (Fine Chemicals, Mumbai, India) were used.

\section{Experimental animals}

Healthy adult Wistar albino rats of either sex were selected randomly for the study. The rats were obtained from the animal house of the Department of Pharmacology, School of Pharmacy, College of Medicine and Health Sciences, University of Gondar. Rats of 12-16 weeks, weighing 160-200 g, were used for the experiment. Each rat was housed in a plastic box cage under standard conditions at $19-25^{\circ} \mathrm{C}$ and was kept under $12 / 12 \mathrm{~h}$ light/dark cycle. The rats were allowed free access to standard pellet feed and water ad libitum. The study was carried out according to the National Research Council Guide for the Care and Use of Laboratory Animals and Organization of Economic Co-operation and Development (OECD) guidelines. ${ }^{15,16}$ Approval from the Research Review Committee of the Department of Pharmacology was also obtained.

\section{Plant material collection and identification}

The fresh leaves of OQ Salzm. ex Decne. (Santalaceae) were collected from Gondar area, Ethiopia, during the month of January 2016. Taxonomic identification was established by Mr Melaku Wondafirash who is an ethnobotanist in the Department of Biology and Biodiversity Management of Addis Ababa University (AAU), and the voucher specimen was deposited in the National Herbarium of AAU with voucher number designated as Mastewal 001.

\section{Preparation of plant extract}

The extraction procedure was carried out according to Girma et $a l^{10}$ with a slight modification. Fresh matured leaves of OQ were washed thoroughly, air dried at room temperature under shade, and coarsely powdered using mortar and pestle. The powder was kept in a tightly closed brown bottle until extraction. Then, $600 \mathrm{~g}$ of this coarsely powdered plant was macerated in $80 \%$ methanol with occasional stirring for 3 days at room temperature to obtain the hydroalcoholic crude extract. After 72 hours, the filtrate was separated from the marc by using a filter paper (Labsman No 1; Jignesh Agency Pvt. Ltd., Mumbai, India). The marc was re-macerated twice. The filtrates were combined and the alcohol was allowed to evaporate in an oven (TF55-1 ALC; France Etuves, Chelles, France) at $40^{\circ} \mathrm{C}$. The percentage yield was found to be $35.83 \% \mathrm{w} / \mathrm{w}$. The dried extract was stored in desiccators until the actual experiment.

\section{Preliminary phytochemical screening}

The crude methanol extract was assessed for secondary metabolites such as alkaloids, tannins, glycosides, steroids, terpenoids, flavonoids, saponins, and anthraquinones using standard methods. ${ }^{17,18}$

\section{Acute toxicity test}

Acute toxicity study was carried out using the limit test dose of $2000 \mathrm{mg} / \mathrm{kg}$ as described by OECD 425 guideline. $^{16}$ Three female albino rats were fasted for 24 hours but allowed free access to water. A limit dose of $2000 \mathrm{mg} / \mathrm{kg}$ of OQ was administered sequentially and animals were observed individually for behavioral profile (alertness, restlessness, irritability, and fearfulness), autonomic profiles (defecation 
and urination), neurologic profile (spontaneous activity, reactivity, touch response, pain response, and gait), physical states such as lacrimation, loss of appetite, tremors, hair erection, salivation, diarrhea, and for morbidity or mortality, after dosing continuously for 2 hours, periodically during the first 24 hours (with special attention given during the first 4 hours) and daily thereafter, for a total of 14 days.

\section{Grouping and dosing of animals}

Animals were randomly assigned to different groups each consisting of six rats. All treatments were given orally 1 hour before the experiment by oral gavage. Doses were determined based on the acute toxicity studies as per OECD guidelines. ${ }^{16}$

\section{Pylorus ligation model}

For the single-dose study: Group 1 (negative control [NC], received distilled water), Group 2 (R50 ie, positive control and received ranitidine $50 \mathrm{mg} / \mathrm{kg}$ ), Group 3 (OQ100 ie, received OQ $100 \mathrm{mg} / \mathrm{kg}$ ), Group 4 (OQ200 ie, received OQ $200 \mathrm{mg} / \mathrm{kg}$ ), and Group 5 (OQ400 ie, received OQ $400 \mathrm{mg} / \mathrm{kg}$ ).

For the repeated dose in a 10-day study: Group 1 or negative control (distilled water), Group 2 or positive control (ranitidine $50 \mathrm{mg} / \mathrm{kg}$ ), and Group 3 (OQ $200 \mathrm{mg} / \mathrm{kg}$ ).

For the repeated dose in a 20-day study: Group 1 or negative control (distilled water), Group 2 or positive control (ranitidine $50 \mathrm{mg} / \mathrm{kg}$ ), and Group 3 (OQ $200 \mathrm{mg} / \mathrm{kg}$ ).

\section{Ethanol-induced ulcer model}

All treatments were given orally 1 hour before the experiment by oral gavage.

For the single-dose study: Group 1 (negative control [NC], received distilled water), Group 2 (S100 ie, positive control and received sucralfate $100 \mathrm{mg} \backslash \mathrm{kg}$ ), Group 3 (OQ100 ie, received OQ $100 \mathrm{mg} / \mathrm{kg}$ ), Group 4 (OQ200 ie, received OQ $200 \mathrm{mg} / \mathrm{kg}$ ), and Group 5 (OQ400 ie, received OQ $400 \mathrm{mg} / \mathrm{kg}$ ).

For the repeated dose in a 10-day study: Group 1 or negative control (distilled water), Group 2 or positive control (sucralfate $100 \mathrm{mg} / \mathrm{kg}$ ), and Group 3 (OQ $200 \mathrm{mg} / \mathrm{kg}$ ).

For the repeated dose in a 20-day study: Group 1 or negative control (distilled water), Group 2 or positive control (sucralfate $100 \mathrm{mg} / \mathrm{kg}$ ), and Group 3 (OQ $200 \mathrm{mg} / \mathrm{kg}$ ).

\section{Anti-ulcer activity evaluation}

Pyloric ligation-induced ulcer model

The Shay rat model described by Dashputre and Naikwade was followed with a slight modification. ${ }^{19}$ Animals were fasted for 48 hours before the study, but had free access to water. After 1 hour of drug treatment, they were anesthetized with ether and the abdomen was opened by a small midline incision below the xiphoid process. Pyloric portion of the stomach was slightly lifted out and ligated. This was performed with caution to avoid traction to the pylorus or damage to its blood supply. The stomach was replaced carefully, and the abdominal wall was closed by interrupted sutures. Rats were sacrificed by an overdose of anesthetic ether after 6 hours of pyloric ligation. The abdomen was opened, cardiac end of the stomach was dissected out, and the contents were drained into a glass tube. The volume of the gastric juice was measured after centrifugation (EppendorfAG-5703DQ713856) at 2000 rpm for 10 minutes. From the supernatant, aliquots $(25$ of $1 \mathrm{ml}$ each) were taken for the determination of $\mathrm{pH}$ and total acidity. Each stomach was examined for lesions in the forestomach portion and indexed according to severity.

The 10-day and 20-day periods were selected based on a study done by Mohod and Modhankar, ${ }^{20}$ and the ulcer was induced on the 10th and 20th day of treatment after having the animals fasted for 48 hours. Scoring the ulcers was done as described below.

\section{Macroscopic evaluation of stomachs}

The stomachs were opened along the greater curvature and rinsed with water to remove gastric contents and blood clots and examined by a $10 \times$ magnifier lens to assess the formation of ulcers. The number of ulcers was counted. Scoring of ulcer was made as follows: ${ }^{19}$

Normal colored stomach (0),

Red coloration (0.5),

Spot ulcer (1),

Hemorrhagic streak (1.5),

Deep ulcers (2),

Perforation (3).

The total mucosal area and total ulcerated area were measured. The ulcer index was then calculated using the following equation: ${ }^{21}$

Ulcer index $=10 / \mathrm{x}$

where $\times$ is the total mucosal area/ulcerated area.

Percentage inhibition of ulceration was calculated as below:

\%inhibition of ulceratio $n$

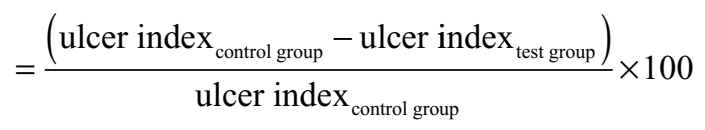

\section{Determination of $\mathrm{pH}$}

An aliquot of $1 \mathrm{ml}$ of gastric juice was diluted with $1 \mathrm{ml}$ of distilled water, and $\mathrm{pH}$ of the solution was measured using $\mathrm{pH}$ meter (Adwa AD8000). ${ }^{19}$ 


\section{Determination of total acidity}

An aliquot of $1 \mathrm{ml}$ of gastric juice was diluted with $1 \mathrm{ml}$ of distilled water and was taken into a $50 \mathrm{ml}$ conical flask and two drops of phenolphthalein indicator was added and titrated with $0.01 \mathrm{~N} \mathrm{NaOH}$ until a permanent pink color was observed. The volume of $0.01 \mathrm{~N} \mathrm{NaOH}$ consumed was noted. The total acidity was expressed as $\mathrm{mEq} / \mathrm{L}$ and calculated by the following formula: ${ }^{19}$

$$
\text { Acidity }=\frac{\mathrm{V}_{\mathrm{NaOH}} \times \mathrm{N} \times 100 \mathrm{mEq} / \mathrm{L}}{0.1}
$$

where $\mathrm{V}$ is volume and $\mathrm{N}$ is normality.

\section{Ethanol-induced gastric ulcer}

The ulcer was induced by administering ethanol following the method by Dashputre and Naikwade with a slight modification. ${ }^{19}$ All the animals were fasted for 48 hours before administration of ethanol. The gastric ulcers were induced in rats by administrating ethanol $(90 \%)(1 \mathrm{ml} / 200 \mathrm{~g})$ orally, after 60 minutes of $80 \%$ methanolic extract and sucralfate treatment. They were kept in specially constructed cages to prevent coprophagia during the experiment. The animals were anesthetized 1 hour later with anesthetic ether, and the stomach was incised along the greater curvature and ulceration was scored as for the pyloric ligation-induced ulcer model.

The 10-day and 20-day repeated-dose approaches were selected based on a study done by Mohod and Bodhankar. ${ }^{20}$ The ulcer was induced on the 10th and 20th day of treatment after having the animals fasted for 48 hours. Scoring the ulcers was done as described above.

\section{Statistical analysis}

Data were expressed as mean \pm standard error of mean and statistically evaluated using one-way analysis of variance, followed by Tukey's multiple comparison tests using SPSS software version 20. $P<0.05$ was considered to be significant.

\section{Results}

\section{Phytochemical screening}

Preliminary phytochemical screening of OQ confirmed the presence of different secondary metabolites, as shown in the Table 1.

\section{Acute toxicity test}

With the acute toxicity test at the limit test dose of 2000 $\mathrm{mg} / \mathrm{kg}$, neither mortality nor changes related to behavioral, autonomic, neurologic, and physical profiles were observed within the first 24 hours and during the 14-day follow-up.
Table I Results for preliminary phytochemical screening of Osyris quadripartita

\begin{tabular}{ll}
\hline Test & Observation \\
\hline Test for alkaloids & Positive \\
Test for phenols & Positive \\
Test for terpenoids & Positive \\
Test for tannins & Positive \\
Test for saponins & Positive \\
Test for anthraquinones & Negative \\
Test for glycosides & Negative \\
Test for steroids & Negative \\
Test for flavonoids & Positive \\
\hline
\end{tabular}

\section{Anti-ulcer effects of $\mathrm{OQ}$}

The effect of the hydroalcoholic leaf extract of OQ on gastric ulcers induced by pylorus ligation and ethanol was assessed by macroscopic evaluation (Figures S1 and S2).

\section{Effects of the leaf extract on pylorus ligation-induced ulcer Single-dose study}

As shown in Table 2, treatment with the extract and the standard drug reduced the volume of gastric secretion, but increased $\mathrm{pH}$ was noted for OQ200, OQ400, and the standard drug. These changes, however, were not significantly different from those of the negative control. Both R50 and OQ400 produced a statistically significant decrease $(P<0.05)$ in the total acidity when compared to the negative control. Ulcer index was significantly reduced by OQ200 $(P<0.05)$, OQ400 $(P<0.001)$ as well as standard drug R50 $(P<0.01)$. In most of the parameters, the extract exhibited a dose-dependent effect. Interestingly, the extract at the highest dose demonstrated better effects than the standard drug in terms of percent inhibition of ulcer score and ulcer index.

\section{Repeated-dose study}

Pretreatment for 10 days

Compared to the negative control, OQ200 exhibited significant reduction in volume of gastric secretion $(P<0.001)$ and total acidity $(P<0.001)$, ulcer score $(P<0.001)$, and ulcer index $(P<0.001)$ similar to the standard drug. The effect of OQ200 was comparable to $\mathrm{R} 50$ regarding percent reduction in ulcer scores (75.48\% vs $76.87 \%$ ) and ulcer index (66.48\% vs $63.72 \%$ ) (Table 3 ).

\section{Pretreatment for 20 days}

Compared to the negative control, OQ200 exhibited significant reduction in volume of gastric secretion $(P<0.001)$ and total acidity $(P<0.001)$, ulcer score $(P<0.001)$, and ulcer index $(P<0.001)$ similar to the standard drug. The effect of OQ200 was comparable to R50 regarding percent reduction 
Table 2 Effect of $O Q$ single-dose pretreatment in pylorus ligation-induced ulcer

\begin{tabular}{llllllll}
\hline Groups & $\begin{array}{l}\text { Volume of } \\
\text { gastric secretion }\end{array}$ & pH & Total acidity & Ulcer score & \multicolumn{2}{l}{$\begin{array}{l}\text { Reduction in ulcer Ulcer index } \\
\text { score (\%) }\end{array}$} & $\begin{array}{l}\text { \% Inhibition of } \\
\text { ulceration }\end{array}$ \\
\hline NC & $3.9 \pm 0.32$ & $3.42 \pm 0.50$ & $84.83 \pm 3.95$ & $5.75 \pm 0.955$ & - & $5.32 \pm 0.62$ & - \\
R50 & $2 \pm 0.30$ & $5.74 \pm 0.76$ & $52.92 \pm 8.13^{\mathrm{a}, *}$ & $3.0 \pm 0.70$ & 47.83 & $2.72 \pm 0.66^{\mathrm{a}, * *}$ & 48.87 \\
OQ100 & $3.86 \pm 0.89$ & $3.23 \pm 0.30$ & $85.08 \pm 3.33$ & $4.83 \pm 0.90$ & 16.00 & $5.03 \pm 0.26$ & 5.45 \\
OQ200 & $2.85 \pm 0.23$ & $4.00 \pm 0.27$ & $72.17 \pm 4.56$ & $3.67 \pm 1.01$ & 36.17 & $3.15 \pm 0.18^{\mathrm{a}, *}$ & 40.79 \\
OQ400 & $2.25 \pm 0.17$ & $5.09 \pm 0.76$ & $55.17 \pm 3.36^{\mathrm{a}, *}$ & $2.08 \pm 0.39^{\mathrm{a}, *}$ & 63.83 & $2.35 \pm 0.25^{\mathrm{a}, * * *}$ & 55.82 \\
\hline
\end{tabular}

Notes: Each value represents the mean \pm SEM for each group $(n=6)$; ${ }^{a}$ against $N C ; * P<0.05 ; * * P<0.01 ; * * * P<0.00$ I.

Abbreviations: OQ, Osyris quadripartita; NC, negative control; R50, ranitidine $50 \mathrm{mg} / \mathrm{kg}$; OQ $100,100 \mathrm{mg} / \mathrm{kg}$ of extract; OQ200, $200 \mathrm{mg} / \mathrm{kg}$ of extract; OQ400, $400 \mathrm{mg} / \mathrm{kg}$ of extract; SEM, standard error of mean.

Table 3 Effect of OQ I0-day pretreatment on pylorus ligation-induced gastric ulcer

\begin{tabular}{|c|c|c|c|c|c|c|c|}
\hline Groups & $\begin{array}{l}\text { Volume of } \\
\text { gastric secretion }\end{array}$ & $\mathrm{pH}$ & Total acidity & Ulcer score & $\begin{array}{l}\text { Reduction in ulcer } \\
\text { score (\%) }\end{array}$ & Ulcer index & $\begin{array}{l}\text { \% Inhibition of } \\
\text { ulceration }\end{array}$ \\
\hline NC & $3.9 \pm 0.31$ & $3.4 I \pm 0.50$ & $84.83 \pm 3.95$ & $5.75 \pm 0.95$ & - & $5.32 \pm 0.62$ & - \\
\hline R50 & $\mathrm{I} .5 \mathrm{I} \pm 0.40^{\mathrm{a}, * * *}$ & $5.85 \pm 0.78^{\mathrm{a}, *}$ & $50.90 \pm 1.32^{\mathrm{a}, * * *}$ & $1.33 \pm 0.166^{\mathrm{a}, * * *}$ & 76.87 & $1.93 \pm 1.85^{\mathrm{a}, * * *}$ & 63.72 \\
\hline OQ200 & $1.7 I \pm 0.10^{\mathrm{a}, * * *}$ & $5.21 \pm 0.36$ & $56.16 \pm 1.85^{\mathrm{a}, * * *}$ & $1.41 \pm 0.15^{\mathrm{a}, * * *}$ & 75.48 & $1.78 \pm 0.03^{\mathrm{a}, * * *}$ & 66.48 \\
\hline
\end{tabular}

Notes: Each value represents the mean \pm SEM for each group $(n=6)$; against $N C ; * P<0.05 ; * * * P<0.00$ I.

Abbreviations: OQ, Osyris quadripartita; NC, negative control; R50, ranitidine $50 \mathrm{mg} / \mathrm{kg}$; OQ200, $200 \mathrm{mg} / \mathrm{kg}$ of extract; SEM, standard error of mean.

in ulcer scores $(79.83 \%$ vs $78.26 \%)$ and ulcer index $(68.42 \%$ vs $66.92 \%$ ) (Table 4 ).

\section{Effects of the leaf extract on ethanol- induced ulcer}

Single-dose study

Both the ulcer score and ulcer index were significantly reduced by OQ200 $(P<0.001)$, OQ400 $(P<0.001)$, and the standard drug S100 $(P<0.001)$. The effect of OQ400 was comparable to R50 regarding percent reduction in ulcer scores $(58.09 \%$ vs $59.49 \%$ ) and ulcer index (62.11\% vs $67.4 \%$ ) (Table 5).

\section{Repeated-dose study}

Pretreatment for 10 days

Both OQ200 and the standard drug produced a significant reduction in ulcer score $(P<0.001)$ and ulcer index $(P<0.001)$ as compared to the negative control. The reduction (\%) in ulcer score and ulcer index was very high to the extract and sucralfate (Table 6).

\section{Pretreatment for 20 days}

Both OQ200 and the standard drug produced a significant reduction in ulcer score $(P<0.001)$ and ulcer index $(P<0.001)$ as compared to the negative control. The percent reduction in ulcer score and ulcer index for the extract was comparable to that of sucralfate (Table 7).

\section{Discussion}

This study was carried out to evaluate the anti-ulcer effect of $80 \%$ methanol leaf extract of OQ on pylorus ligation-induced and ethanol-induced gastric ulcer models. The $35.83 \%$ plant extraction yield is similar with the $40.11 \%^{6}$ and $32.75 \%{ }^{10}$ reported in previous studies done in Ethiopia, thus supporting that hydroalcoholic solvent possesses a good extracting potential. Methanol releases more diverse phytochemicals such as anthocyanins, tannins, saponins, terpenoids, xanthoxylines, totarol, quassinoids, lectones, flavones, phenols, and polyphenols than other extraction solvents. ${ }^{22,23}$ The acute toxicity study revealed that the plant extract was safe in rats at a limit dose of $2000 \mathrm{mg} / \mathrm{kg}$ and that the median lethal dose $\left(\mathrm{LD}_{50}\right)$ of the extract is above $2000 \mathrm{mg} / \mathrm{kg}$. The finding supports the work done on mice in another study. ${ }^{10}$ In the preliminary phytochemical screening, the $80 \%$ methanol leaf extract of OQ was positive for flavonoids, saponins, tannins, phenols, terpenoids, and alkaloids. These secondary metabolites are effective as antioxidant, antineoplastic, anti-ulcer, anti-inflammatory, and

Table 4 Effect of OQ 20-day pretreatment on pylorus ligation-induced gastric ulcer

\begin{tabular}{|c|c|c|c|c|c|c|c|}
\hline Groups & $\begin{array}{l}\text { Volume of gastric } \\
\text { secretion }\end{array}$ & $\mathrm{pH}$ & Total acidity & Ulcer Score & $\begin{array}{l}\text { Reduction in ulcer } \\
\text { score (\%) }\end{array}$ & Ulcer index & $\begin{array}{l}\text { \% Inhibition of } \\
\text { ulceration }\end{array}$ \\
\hline NC & $3.9 \pm 0.31$ & $3.4 I \pm 0.50$ & $84.83 \pm 3.95$ & $5.75 \pm 0.95$ & - & $5.32 \pm 0.62$ & - \\
\hline $\mathbf{R 5 0}$ & $\mathrm{I} . \mathrm{II} \pm 0.06^{\mathrm{a}, * * * *}$ & $6.05 \pm 0.23^{\mathrm{a}, *}$ & $48.67 \pm 3.14^{\mathrm{a}, * * *}$ & $1.25 \pm 0.1 \mathrm{I}^{\mathrm{a}, * * *}$ & 78.26 & $1.76 \pm 0.16^{\mathrm{a}, * * *}$ & 66.92 \\
\hline OQ200 & $1.26 \pm 0.17^{\mathrm{a}, * * * *}$ & $5.53 \pm 0.92$ & $53.67 \pm 1.93^{\mathrm{a}, * * * *}$ & 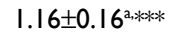 & 79.83 & $1.68 \pm 0.27^{\mathrm{a}, * * *}$ & 68.42 \\
\hline
\end{tabular}

Notes: Each value represents the mean \pm SEM for each group $(n=6)$; against $N C ; * P<0.05 ; * * * P<0.00$ I.

Abbreviations: OQ, Osyris quadripartita; NC, negative control; R50, ranitidine $50 \mathrm{mg} / \mathrm{kg}$; OQ200, $200 \mathrm{mg} / \mathrm{kg}$ of extract; SEM, standard error of mean. 
Table 5 Effect of the leaf extract of $\mathrm{OQ}$ on ulcer score and ulcer index in ethanol-induced gastric ulcer in single-dose study

\begin{tabular}{lllll}
\hline Groups & Ulcer score & Reduction in ulcer score (\%) & Ulcer index & \% Inhibition of ulceration \\
\hline NC & $5.75 \pm 0.69$ & - & $5.12 \pm 0.28$ & - \\
S100 & $2.33 \pm 0.33^{\mathrm{a}, * * * *}$ & 59.49 & $1.67 \pm 0.3 \mathrm{I}^{\mathrm{a}, * * * *}$ & 67.4 \\
OQ200 & $2.91 \pm 0.20^{\mathrm{a}, * *}$ & 49.39 & $2.34 \pm 0.13^{\mathrm{a}, * * *}$ & 54.3 \\
OQ400 & $2.41 \pm 0.32^{\mathrm{a}, * * *}$ & 58.09 & $1.94 \pm 0.24^{\mathrm{a}, * * *}$ & 62.11 \\
\hline
\end{tabular}

Notes: Each value represents the mean \pm SEM for each group $(n=6)$; against $N C ; * * P<0.01 ; * * * P<0.001$.

Abbreviations: OQ, Osyris quadripartita; NC, negative control; S100, sucralfate $100 \mathrm{mg} / \mathrm{kg}$; OQ200, $200 \mathrm{mg} / \mathrm{kg}$ of extract; OQ400, $400 \mathrm{mg} / \mathrm{kg}$ of extract; SEM, standard error of mean.

Table 6 Effect of OQ 10-day pretreatment on ethanol-induced gastric ulcer

\begin{tabular}{lllll}
\hline Groups & Ulcer score & Reduction in ulcer score (\%) & Ulcer index & \% Inhibition of ulceration \\
\hline NC & $5.75 \pm 0.69$ & - & $5.12 \pm 0.27$ & - \\
S100 & $1.08 \pm 0.15^{\mathrm{a}, * * * *}$ & 81.22 & $1.04 \pm 0.36^{\mathrm{a}, * * * *}$ & 79.69 \\
OQ200 & $1.5 \pm 0.22^{\mathrm{a}, * * *}$ & 73.91 & $1.46 \pm 0.29^{\mathrm{a}, * * * *}$ & 71.48 \\
\hline
\end{tabular}

Notes: Each value represents the mean \pm SEM for each group $(n=6) ;{ }^{a}$ against $N C ; * * * P<0.00$ I.

Abbreviations: OQ, Osyris quadripartita; NC, negative control; SI00, sucralfate $100 \mathrm{mg} / \mathrm{kg}$; OQ200, $200 \mathrm{mg} / \mathrm{kg}$ of extract; SEM, standard error of mean.

Table 7 Effect of OQ 20-day pretreatment on ethanol-induced gastric ulcer

\begin{tabular}{lllll}
\hline Groups & Ulcer score & Reduction in ulcer score (\%) & Ulcer index & \% Inhibition of ulceration \\
\hline NC & $5.75 \pm 0.69$ & - & $5.12 \pm 0.27$ & - \\
S100 & $0.75 \pm 0.1 I^{\mathrm{a}, * * * *}$ & 86.96 & $0.54 \pm 0.28^{\mathrm{a}, * * *}$ & 89.45 \\
OQ200 & $0.91 \pm 0.15^{\mathrm{a}, * * *}$ & 84.17 & $0.75 \pm 0.24^{\mathrm{a}, * * *}$ & 85.35 \\
\hline
\end{tabular}

Notes: Each value represents the mean \pm SEM for each group $(n=6) ;{ }^{\text {aggainst }} \mathrm{NC}$; $* * * P<0.00$ I.

Abbreviations: OQ, Osyris quadripartita; NC, negative control; SI00, sucralfate $100 \mathrm{mg} / \mathrm{kg}$; OQ200, $200 \mathrm{mg} / \mathrm{kg}$ of extract; SEM, standard error of mean.

immune stimulating agents. ${ }^{20,24-28}$ Flavonoids are thought to increase mucosal prostaglandin content, decrease histamine secretion from mast cells by inhibition of histidine decarboxylase, inhibit Helicobacter pylori growth, act as free radical scavengers, and inhibit $\mathrm{H}+/ \mathrm{K}+-\mathrm{ATPase} .^{25,27,29}$ Saponins may activate mucous membrane protective factors, and tannins render the outermost layer of the mucosa less permeable, for instance, to chemical irritation. ${ }^{27}$ In addition, terpenoids and alkaloid compounds are also reported to have potent activity against gastric ulcers. ${ }^{30,31}$

The etiology of peptic ulcer is unknown in most of the cases, yet it is generally accepted that it results from an imbalance between aggressive factors and the maintenance of mucosal integrity through the endogenous defense mechanisms. To regain the balance, different therapeutic agents are used to inhibit the gastric acid secretion or to boost the mucosal defense mechanisms by increasing mucosal production, stabilizing the surface epithelial cells, or interfering with the prostaglandin synthesis. ${ }^{20,29,32-34}$

Pyloric ligation-induced ulcer model is an important method for the measurement of mean ulcer index in ulcerogenesis. Gastric ulceration in this method may be the stressinduced secretion of $\mathrm{HCl}$ in excess amounts from the parietal cells and autodigestion of mucosa by the gastric juice. ${ }^{20,29,32}$ Free radicals may also be associated since studies have shown changes in the antioxidant status following pylorus ligationinduced ulceration in rats. ${ }^{29}$ In the present study, different doses of the extract $(100,200$, and $400 \mathrm{mg} / \mathrm{kg}$ ) were evaluated for their effect on volume of gastric secretion, $\mathrm{pH}$, total acidity, ulcer score, and ulcer index along with the standard drug ranitidine $(50 \mathrm{mg} / \mathrm{kg})$. In the single-dose study of the pylori ligation model, OQ100 did not show any better activity when compared to the negative control. This indicates that the low dose of the extract is not an adequate dose to produce ulcer healing. This model showed that the highest dose of the plant extract (OQ400) has got better antisecretory activity as evidenced by reduction in the mean volume of gastric secretion, rise in $\mathrm{pH}$, and reduction in total acidity $(P<0.01)$ compared to the negative control. Significant reduction in ulcer index (measure of ulcerated area) was noted for OQ200 $(P<0.05)$ and OQ400 $(P<0.001)$ as compared to the negative control. While R50 has more antisecretory effect than the extract, OQ400 amazingly exhibited a better reduction of ulcer index than the standard drug (2.35 \pm 0.25 vs $2.72 \pm 0.66$ ), which might be due to more combined cytoprotective and antisecretory activity effect of the extract than of the standard drug. Flavonoids are suggested to possess both these effects. ${ }^{25,27}$ The better reduction in ulcer index noted for OQ400 compared with the standard drug R50 is in line with a report by Melese et $\mathrm{al}^{21}$ where the aqueous extract of Plantago lanceolata L. at a dose of $400 \mathrm{mg} / \mathrm{kg}$ showed a 
better ulcer inhibition than the standard drug ranitidine. Such findings strengthen the search for novel agents by tapping the rich herbal drugs used in folk medicine.

A repeated-dose study for two different time durations (10 and 20 days) was also carried out in the pylorus ligationinduced ulcer model and the effect of the extract on improvement of ulcer lesions was observed. The lowest effective dose (OQ200) in the single-dose study was chosen since repeated administration of the higher dose may not be safe. Compared to the negative control, pretreatment with R50 and OQ200 for 10 and 20 days produced a significant reduction in volume of gastric secretion $(P<0.001)$ and total acidity $(P<0.001)$, strengthening the antisecretory activity of the plant extract. Ulcer score $(P<0.001)$ and ulcer index $(P<0.001)$ were also decreased significantly. The percentage of ulcer inhibition slightly increased in a time-dependent manner from 10-day pretreatment of OQ200 (66.48\%) to 20-day pretreatment $(68.36 \%)$. When compared to $55.82 \%$ ulcer inhibition by the most effective dose (OQ400) in the single-dose study, the 10 and 20 days of pretreatment of OQ200 showed a better ulcer inhibition (66.48\% and $68.42 \%$, respectively). This suggests repeated dosing produces cumulative effect, which is better than single dosing.

The ability of the gastric mucosa to resist injury by endogenous secretions (acid, pepsin, and bile) and ingested irritants (eg, alcohol, nonsteroidal anti-inflammatory drugs [NSAIDs]) can be attributed to a number of factors that have been collectively referred to as "mucosal defense". ${ }^{35}$ The concept of gastric cytoprotection against various necrotizing agents has been routinely used to assess the anti-ulcer potential of different compounds. The ethanol-induced acute gastric mucosal injury model is considered to be one of the widely used experimental models of ulcer disease. ${ }^{36}$ Ethanol easily penetrates the gastric mucosa and causes gastric ulcer 1 hour after administration. Ulceration is due to a decrease in gastric mucus, prostaglandin levels, glutathione, mucosal blood flow, and bicarbonate secretion as well as an increase in lipid peroxidation, oxidative stress, leukotriene production, and generation of free radicals leading to cell and membrane damage. It has been reported that leukotriene antagonist and 5-lipoxygenase inhibitors are capable of inhibiting alcohol and NSAID-induced gastric ulceration in rats. ${ }^{20,37,38}$

In the present study, the ethanol-induced model was employed to confirm the gastric cytoprotective effect of the plant extract. This test excluded the $100 \mathrm{mg} / \mathrm{kg}$ dose as it was noted to be least effective in the pylorus ligation model. Extract- and standard drug-treated groups showed a significant reduction (at least $P<0.01$ ) in both the ulcer score and ulcer index. The extract effect increases with the dose and is comparable with that of the standard drug. The repeated-dose study for ethanol-induced ulcer model showed a significant reduction in ulcer score $(P<0.001)$ and ulcer index $(P<0.001)$ in the 10 -day and 20 -day pretreatment with OQ200 and S100. This finding signifies that the extract possesses a gastroprotective effect, which is as good as the standard drug. The repeated-dose study with OQ200 showed a better reduction in percentage of ulcer inhibition, ( $71.48 \%$ for 10 days and $85.35 \%$ for 20 days) as compared to the single-dose study for OQ200 (54.3\%) and OQ400 $(62.11 \%)$. This suggests that the cumulative ulcer healing effect of the extract is better than that of the single dose in this model. The results of the present study showed that the OQ leaf extract was capable of inhibiting gastric lesions formed by ethanol. Absolute alcohol would extensively damage the gastric mucosa leading to increased infiltration of neutrophils, which are a major source of inflammatory mediators. Therefore, suppression of neutrophil infiltration during inflammation was found to enhance gastric ulcer healing. ${ }^{33,34,39}$ OQ leaf extract has been shown to contain anti-inflammatory activity, ${ }^{13}$ and it is speculated that the gastroprotective effect exerted by this plant could be credited to its anti-inflammatory property. Compounds that act as antioxidants or activate the redox system are important for restoring gastric tissue. ${ }^{30,40}$ Therefore, strong ulcer healing effect of the extract in the ethanol-induced model might also be related to the antioxidant activity of the plant, which is well demonstrated in previous studies. ${ }^{14}$ Flattening of the mucosal folds observed in the present study also suggests the gastroprotective effect of the extract. Different reports showed that the changes in the gastric motility may play a role in the development and prevention of experimental gastric lesions. Relaxation of circular muscles will increase the mucosal area to being exposed to necrotizing agents and reduce the volume of the gastric irritants on rugal crest, leading to protection of the gastric mucosa against damage. ${ }^{33,34,39}$

\section{Conclusion}

The findings in this study confirm, the absence of oral acute toxicity at the doses employed, and presence of anti-ulcer pharmacologic activity of OQ. Its efficacy is comparable to the standard drugs, with repeated administration being more effective than single dosing. Anti-ulcer effects may be related to antisecretory as well as cytoprotective activities of one or more of the identified phytochemicals. Thus, the present work validates the use of OQ for gastric ulcer in the Ethiopian folk medicine, and further studies shall focus on isolation of specific phytochemicals and elucidating mechanisms of action. 


\section{Acknowledgment}

The authors are very thankful to the University of Gondar for allowing them to use the laboratory facilities.

\section{Disclosure}

The authors report no conflicts of interest in this work.

\section{References}

1. Tanih NF, Ndip LM, Clarke AM, Ndip RN. An overview of pathogenesis and epidemiology of Helicobacter pylori infection. Afr J Microbiol Res. 2010;4(6):426-436.

2. Lavnya A, Kumar MP, Anbu J, Anjana A, Ayyasay S. Antiulcer activity of Canavalia virosa (ROXB) W\&A leaves in animal model. Int J Life Sci Pharma Res. 2012;2(4):39-43.

3. Panda V, Sonkamble M. Anti-ulcer activity of Ipomoea batatas tubers (sweet potato). Funct Foods Health Dis. 2012;2(3):48-61.

4. Hedberg I, Edwards S. Pittosporaceae to Araliaceae. In: Hedberg I, Edwards S, editors. Flora of Ethiopia and Eritrea. Vol 3. Ethiopia: Addis Ababa: National Herbarium, Biology Department, Science Faculty, Addis Ababa University and Sweden: The Department of Systematic Botany, Uppsala University; 1989.

5. Herrera CM. The annual cycle of Osyris quadripartita, a hemiparasitic dioecious shrub of Mediterranean scrublands. JEcol. 1984;72(3):1065-1078.

6. Taddese S, Asres K, Gbre-Mariam T. In vivo antimicrobial activities of some selected topically applied medical plants. Ethiop Pharma J. 2003;21:39-41.

7. Suleman S, Alemu T. Survey on utilization of ethnomedicinal plants in Nekemte town, East Wellega (Oromia), Ethiopia. J Herbs Spices Med Plants. 2012;18(1):34-57.

8. Enyew A, Asfaw Z, Kelbessa E, Nagappan R. Ethnobotanical study of traditional medicinal plants in and around Fiche district, Central Ethiopia. Curr Res J Biol Sci. 2014;6(4):154-167.

9. Yineger H, Kelbessa E, Bekele T, Lulekal E. Plants used in traditional management of human ailments at Bale Mountains National Park, Southeastern Ethiopia. J Med Plants Res. 2008;2(6):132-153.

10. Girma S, Giday M, Erko B, Mamo H. Effect of crude leaf extract of Osyris quadripartita on Plasmodium berghei in Swiss albino mice. BMC Complement Altern Med. 2015;15:184.

11. Gebeyehu G, Asfaw Z, Enyew A, Raja N. Ethnobotanical study of traditional medicinal plants and their conservation status in Mecha Woreda, West Gojjam zone of Ethiopia. Int J Pharm Health Care Res. 2014;2(3):137-154.

12. Getaneh S, Girma Z. An ethnobotanical study of medicinal plants in Debre Libanos Wereda, Central Ethiopia. Afr J Plant Sci. 2014;8(7):366-379.

13. Gómez ME, Ayuso MJ, Toro MV. Activity of Osyris quadripartita salzm. methanol extract on capillary permeability in rats. Phytother Res. 1995;9(7):528-530.

14. Rached W, Benamar H, Bennaceur M, Marouf A. Screening of the antioxidant potential of some Algerian indigenous plants. J Biol Sci. 2010;10(4):316-324.

15. National Research Council. Guide for the Care and Use of Laboratory Animals. 8th ed. Washington, DC: The National Academies Press; 1996.

16. Organization for Economic Cooperation and Development. OECD Guidelines for the Testing of Chemicals. Acute Oral Toxicity -Up-AndDown-Procedure. UDP; 425. France: OECD Publishing; 2008.

17. Njoku VO. and Obi C. Phytochemical constituents of some selected medicinal plants. Afr J Pure Appl Chem. 2009;3(11):228-233.

18. Wadood A, Ghufran M, Jamal SB, Naeem M, Khan A, Ghaffar R. Phytochemical analysis of medicinal plants occurring in local area of Mardan. Biochem Anal Biochem. 2013;2(4):1-4.
19. Dashputre NL, Naikwade NS. Evaluation of anti-ulcer activity of methanolic extract of Abutilon indicum Linn leaves in experimental rats. Int J Pharm Sci Drug Res. 2011;3(2):97-100.

20. Mohod SM, Bodhankar SL. Evaluation of antiulcer activity of methanolic extract of leaves of Madhuca indica J.F Gmel in rats. Pharmacologyonline. 2011;3:203-213.

21. Melese E, Asres K, Asad M, Engidawork E. Evaluation of the antipeptic ulcer activity of the leaf extract of Plantago lanceolata L. in rodents. Phytother Res. 2011;25(8):1174-1180.

22. Tiwari P, Kumar B, Kaur M, Kaur G, Kaur H. Phytochemical screening and extraction: a review. Int Pharm Sci. 2011;1(1):98-106.

23. Cowan MM. Plant products as antimicrobial agents. Clin Microbiol Rev. 1999;12(4):564-582.

24. Paguigan ND, Castillo DH, Chichioco-Hernandez CL. Anti-ulcer activity of leguminosae plants. Arq Gastroenterol. 2014;51(1):64-67.

25. Repetto MG, Llesuy SF. Antioxidant properties of natural compounds used in popular medicine for gastric ulcers. Braz J Med Biol Res. 2002;35(5):523-534.

26. de Sousa Falcão H, Leite JA, Barbosa-Filho JM, et al. Gastric and duodenal antiulcer activity of alkaloids: a review. Molecules. 2008;13(12):3198-3223.

27. Borrelli F, Izzo AA. The plant kingdom as a source of anti-ulcer remedies. Phytother Res. 2000;14(8):581-591.

28. Reddy VP, Sudheshna G, Afsar SK, et al. Evaluation of anti-ulcer activity of Citrullus colocynthis fruit against pylorus ligation induced ulcers in male Wistar rats. Int J Pharm Pharm Sci. 2012;4(2):446-451.

29. Sharath SS, Preethy J, Kumar GS, et al. Screening for anti-ulcer activity of Convolvulus pluricaulis using pyloric ligation method in Wister rats. Int J Pharm Sci Res. 2015;6(1):89-99.

30. Klein-Júnior LC, Santin JR, Niero R, de Andrade SF, Cechinel-Filho V. The therapeutic lead potential of metabolites obtained from natural sources for the treatment of peptic ulcer. Phytochem Rev. 2012: 11(4):567-616.

31. Mitra P, Ghosh T, Mitra PK. Anti gastric ulcer activity of Amaranthus spinosus Linn. leaves in aspirin induced gastric ulcer in rats and the underlying mechanism. SMU Med J. 2014;1(2):313-328.

32. Raju D, Ilango K, Chitra V, Ashish K. Evaluation of anti-ulcer activity of methanolic extract of Terminalia chebula fruits in experimental rats. J Pharm Sci Res. 2009;1(3):101-107.

33. Al-Radahe S, Ahmed KA, Salama S, et al. Anti-ulcer activity of Swietenia mahagoni leaf extract in ethanol-induced gastric mucosal damage in rats. J Med Plants Res. 2013;7(16):988-997.

34. Abdulla MA, AL-Bayaty FH, Younis LT, Abu Hassa MI. Anti-ulcer activity of Centella asiatica leaf extract against ethanol-induced gastric mucosal injury in rats. J Med Plants Res. 2010;4(13):1253-1259.

35. Wallace JL. Nonsteroidal anti-inflammatory drugs and the gastrointestinal tract. Mechanisms of protection and healing: current knowledge and future research. Am J Med. 2001;110(1A):19S-23S.

36. Shawon L, Gautam P. An overview of the current methodologies used for evaluation of gastric and duodenal anti-ulcer agents. Pharmacologia. 2012;3(8):249-257.

37. Nordin N, Salama SM, Golbabapour S, et al. Anti-ulcerogenic effect of methanolic extracts from Enicosanthellum pulchrum (King) Heusden against ethanol-induced acute gastric lesion in animal models. PLoS One. 2014;9(11):e111925.

38. Roy SP, Prajapati K, Gupta R, et al. Evaluation of anti-ulcer effects of ethanolic extract of Delonix regia flower. Indian J Res Pharm Biotechnol. 2013;1(3):440-445.

39. Al Batran R, Al-Bayaty F, Jamil Al-Obaidi MM, et al. In vivo antioxidant and antiulcer activity of Parkia speciosa ethanolic leaf extract against ethanol-induced gastric ulcer in rats. PLoS One. 2013;8(5):e64751.

40. Hussain L, Akash MS, Naseem S, Rehman K, Ahmed KZ. Antiulcerogenic effects of Salmalia malabarica in gastric ulceration--pilot study. Adv Clin Exp Med. 2015;24(4):595-605. 


\section{Supplementary materials}
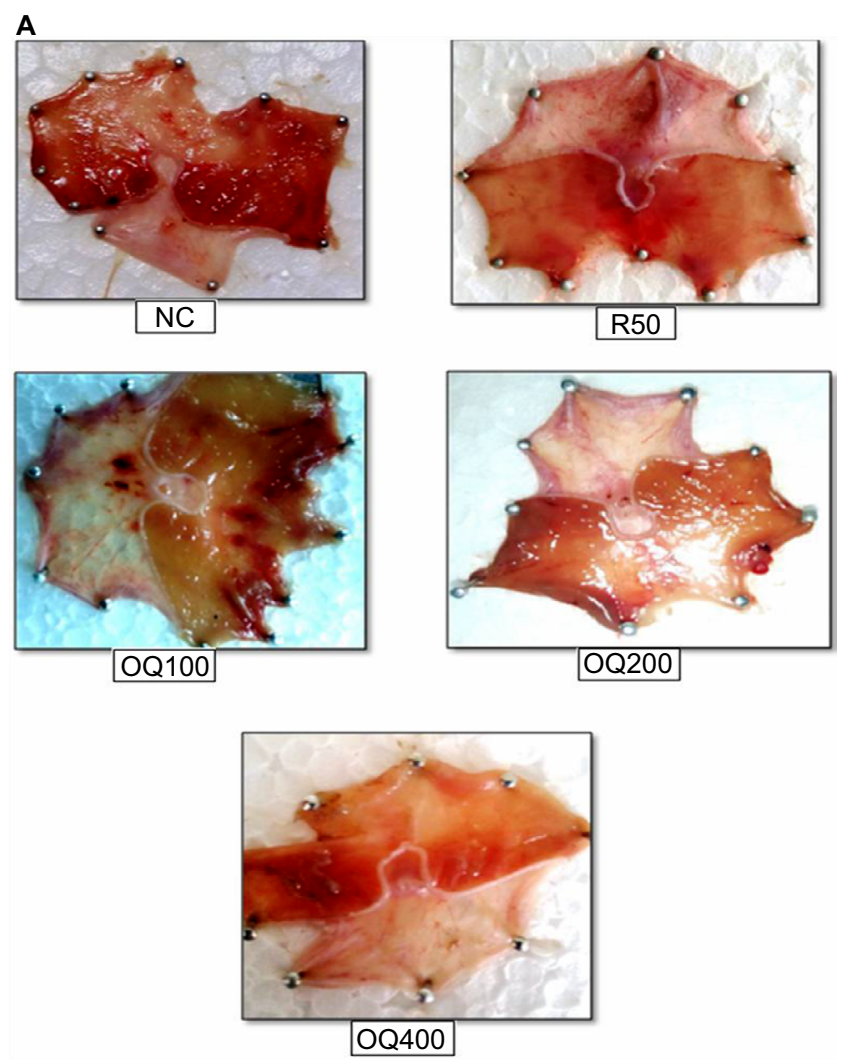

B
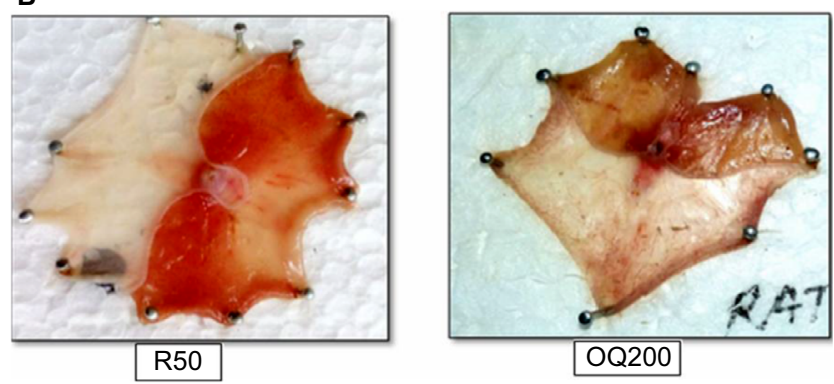

C
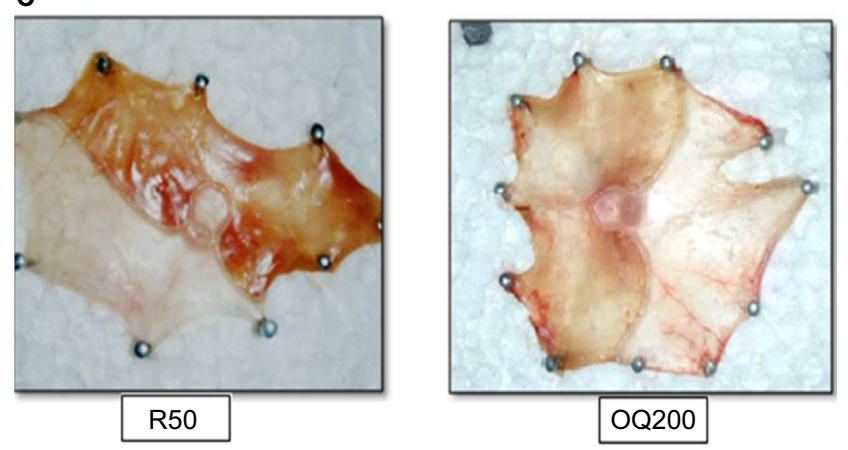

Figure I (A) Pyloric ligation method: single-dose study. (B) Pyloric ligation method: 10 days of pretreatment or repeated-dose study. (C) Pyloric ligation method: 20 days of pretreatment or repeated-dose study.

Notes: As shown in (A), the extract at the highest dose (OQ400) demonstrated better effects than the standard drug (R50) in terms of percent inhibition of ulcer score and ulcer index. (B and C) demonstrate that the extract $200 \mathrm{mg} / \mathrm{kg}$ dose possess better anti-ulcer effect when taken repeatedly.

Abbreviations: OQ, Osyris quadripartita; NC, negative control; R50, ranitidine $50 \mathrm{mg} / \mathrm{kg} ;$ OQ $100,100 \mathrm{mg} / \mathrm{kg}$ of extract; OQ200, $200 \mathrm{mg} / \mathrm{kg}$ of extract; OQ400, $400 \mathrm{mg} / \mathrm{kg}$ of extract. 
A
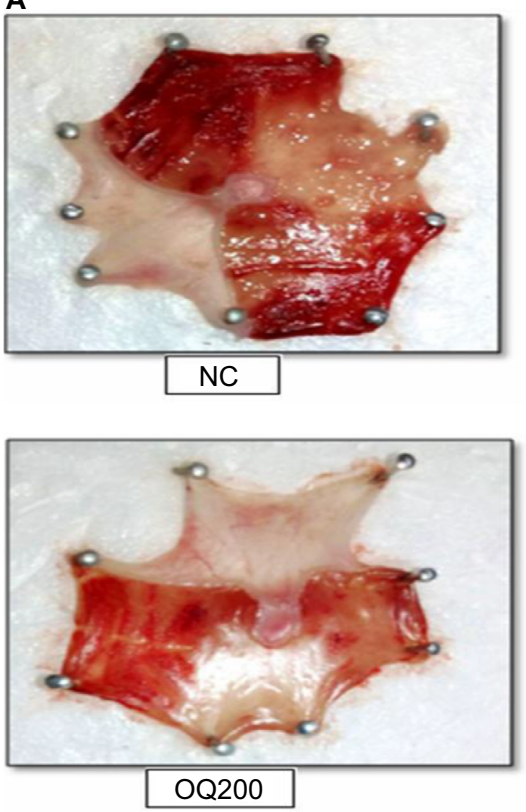

B

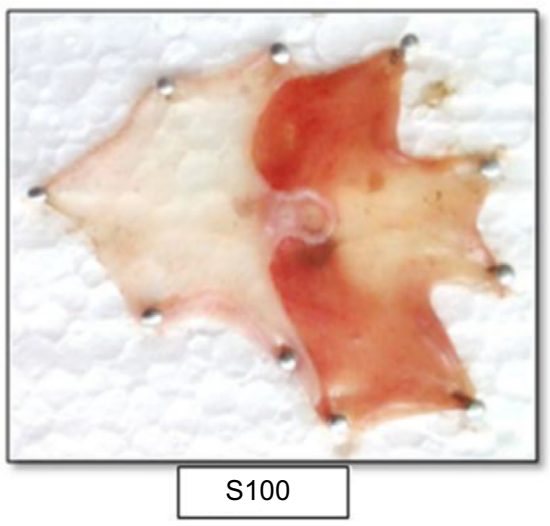

C

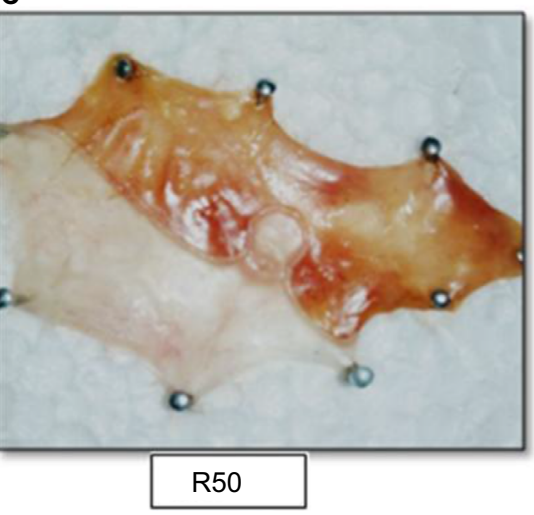

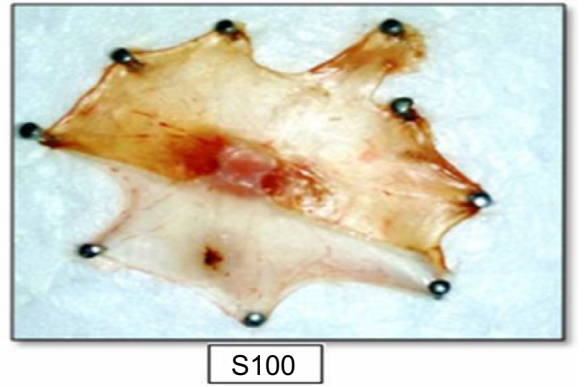
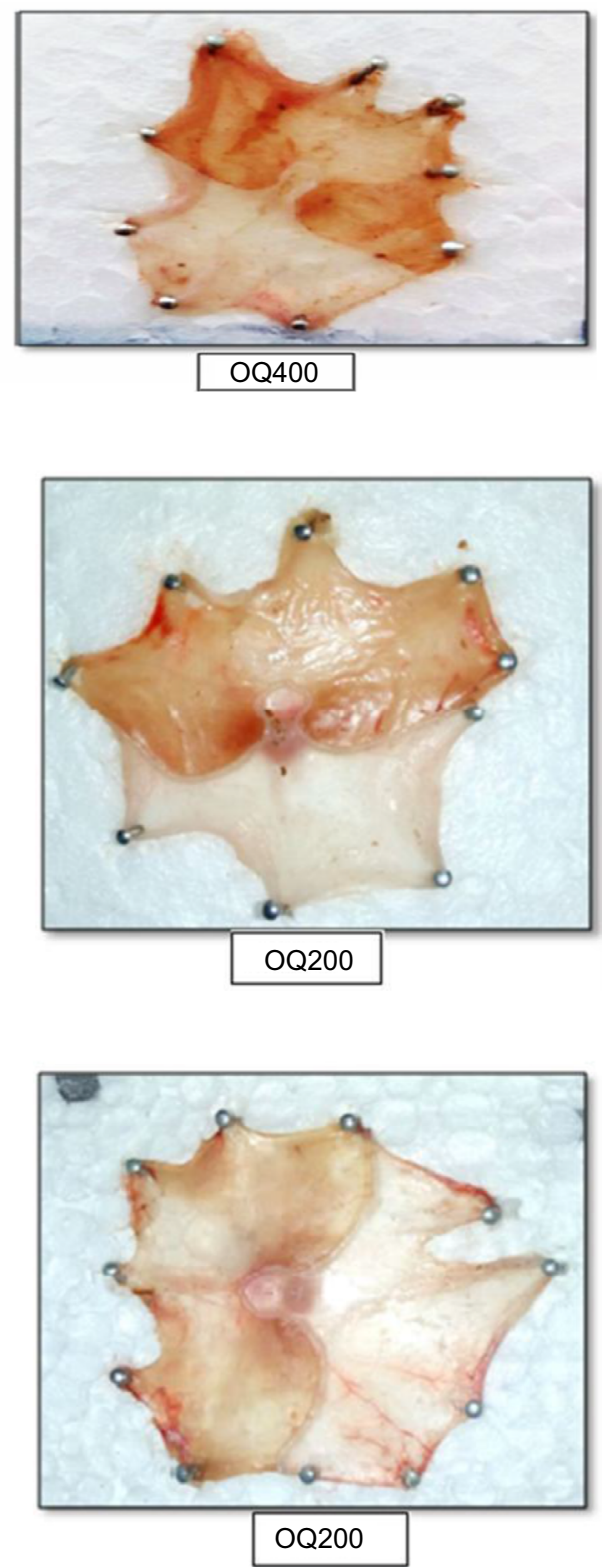

Figure 2 (A) Ethanol-induced ulcer: single-dose study. (B) Ethanol-induced model: 10 days of pretreatment or repeated-dose study. (C) Ethanol-induced model: 20 days of pretreatment or repeated-dose study.

Notes: As shown in (A), the extract demonstrated better anti-ulcer effect at the higher dose (OQ400). (B and C) demonstrate that the extract 200 mglkg dose possess better anti-ulcer effect when taken repeatedly.

Abbreviations: OQ, Osyris quadripartita; R50, ranitidine $50 \mathrm{mg} / \mathrm{kg}$; NC, negative control; SI00, sucralfate $100 \mathrm{mg} / \mathrm{kg} ; \mathrm{OQ} 200,200 \mathrm{mg} / \mathrm{kg}$ of extract; OQ400, $400 \mathrm{mg} / \mathrm{kg}$ of extract; R50, ranitidine $50 \mathrm{mg} / \mathrm{kg}$. 
Journal of Experimental Pharmacology

\section{Publish your work in this journal}

The Journal of Experimental Pharmacology is an international, peerreviewed, open access journal publishing original research, reports, reviews and commentaries on all areas of laboratory and experimental pharmacology. The manuscript management system is completely online and includes a very quick and fair peer-review system.

\section{Dovepress}

Visit http://www.dovepress.com/testimonials.php to read real quotes from published authors.

Submit your manuscript here: https://www.dovepress.com/journal-of-experimental-pharmacology-journal 